California Western School of Law

CWSL Scholarly Commons

Faculty Scholarship

2016

Food Labeling and Consumer Associations with Health, Safety, and Environment

Joanna K. Sax

California Western School of Law, jsax@cwsl.edu

Neal Doran

University of California - San Diego

Follow this and additional works at: https://scholarlycommons.law.cwsl.edu/fs

Part of the Molecular, Genetic, and Biochemical Nutrition Commons, and the Public Health Education and Promotion Commons

Recommended Citation

Sax, Joanna and Doran, Neal, Food Labeling and Consumer Associations with Health, Safety and Environment (May 31, 2016). 44 Journal of Law, Medicine \& Ethics 630-38 (2016).

This Article is brought to you for free and open access by CWSL Scholarly Commons. It has been accepted for inclusion in Faculty Scholarship by an authorized administrator of CWSL Scholarly Commons. For more information, please contact alm@cwsl.edu. 


\title{
Food Labeling and Consumer Associations with Health, Safety, and Environment
}

\author{
Joanna K. Sax and Neal Doran
}

\section{Introduction}

Sectors of the public and consumer advocacy groups are increasingly calling for a variety of food labeling measures, ${ }^{1}$ particularly regarding food derived from genetically modified organisms/genetically engineered (GMO/GE) and the use of the label "natural." The potential for new labeling regulations raises questions about the information that consumers either receive or believe they receive from such labels. Articles in the popular press and advocates of mandatory labeling cite the right of consumers to know the contents of their food, with a special emphasis on consumer concerns for health, safety, and the environment. ${ }^{2}$ The purpose of the current study was to examine the extent to which consumers associate health, safety, and the environment with specific labels and specific food products.

Recent proposals for mandatory labels focus on GMO/GE labeling. ${ }^{3}$ Vermont passed a law that requires some food, derived from genetic engineering techniques, be labeled. ${ }^{4}$ The stated purpose of the Vermont law is to allow consumers to make informed decisions about public health, food safety, environmental impacts, decrease consumer confusion and deception by not allowing GE food to be labeled as "natural," and protect religious practices. ${ }^{5}$

Joanna K. Sax, J.D., Ph.D., is a Professor of Law at California Western School of Law (San Diego, CA). She received her Ph.D. in Cell and Molecular Biology from the University of Pennsylvania School of Medicine and her J.D. from the University of Pennsylvania Law School (Philadelphia, PA). Neal Doran, Ph.D., is an Associate Professor of Psychiatry at the University of California, San Diego (San Diego, CA) and Director of Clinical Improvement, Office of Mental Health at the Veteran's Affairs San Diego Healthcare System (San Diego, CA). He received his Ph.D. in Clinical Psychology from the University of Illinois at Chicago (Chicago, Il).
At the federal level, in July 2016, Congress passed and the President signed the "National Bioengineered Food Disclosure Standard," which pre-empts state action (including Vermont) and requires that a disclosure such as a "text, symbol, or electronic or digital link" or "other reasonable disclosure options" be placed on genetically engineered food. ${ }^{6}$ Prior to this, on November 19, 2015, the FDA de-regulated the first GMO/GE animal, AquAdvantage salmon. ${ }^{7}$ At the same time, the FDA acknowledged that many consumers want to know if food is derived from GMO/ GE technology or not, thus upon the de-regulation of the salmon, the FDA issued two guidance documents regarding voluntary labeling. ${ }^{8}$

Food labeling requirements exist in order to provide information to consumers, but this is not always as easy as it seems. While some labeling requirements are mandated, such as those required under the Nutrition Labeling and Education Act, other content on labels is created by the manufacturer. By way of example, manufacturers may label their product as "natural" even though this term has no clear definition and the FDA has consistently rejected calls for a definition. ${ }^{9}$ According to the FDA, "From a food science perspective, it is difficult to define a food product that is 'natural' because the food has probably been processed and is no longer the product of the earth." ${ }^{10}$

It is unclear what could be considered natural. Thousands of years of conventional breeding mean that the food supply is genetically modified. Put differently, consumers are eating domesticated crops that are no longer genetically identical to the wild-type variety either through conventional breeding or GMO/GE technology. ${ }^{11}$ Conventional selective breeding uses a variety of techniques, including mutation breeding, to obtain a desired trait, such as pest resistance. ${ }^{12} \mathrm{GMO} /$ 
GE technology, in contrast to conventional breeding, can be used to introduce a gene to provide resistance against a particular pest. ${ }^{13}$ Agriculture scientists and farmers may prefer one methodology over another to obtain the desired result.

The food supply is changing. In the 1990s, GMO food crops were first introduced into the food supply. ${ }^{14} \mathrm{~A}$ variety of new techniques allowed breeders to create genetic modifications that could not be created through conventional breeding, such as the insertion of a particular gene or utilizing RNA interference. ${ }^{15}$ Prior to the introduction of food derived from GMOs into the marketplace, a Coordinated Framework was created to incorporate the FDA, United States Department of Agriculture (USDA), and Environmental Pro- ducted by the New York Times found that most of the consumers who expressed concerns about food from GMOs worried about negative health effects. ${ }^{22}$ Even though the scientific consensus is that food derived from GMOs/GE is as safe as conventional food, the consumer perception is different.

A component to providing labels to consumers is understanding their preferences. According to the Organic Consumer Association, the demand for organic food is greater than the domestic supply. ${ }^{23}$ Organic products cannot contain GMOs. ${ }^{24}$ Thus, a tension in the marketplace now exists between organic and GMO products. It is important to understand why and which consumers might prefer organic to other types of food. A report by Hughner and col-

It is unclear what could be considered natural. Thousands of years of conventional breeding mean that the food supply is genetically modified. Put differently, consumers are eating domesticated crops that are no longer genetically identical to the wild-type variety - either through conventional breeding or GMO/GE technology. Conventional selective breeding uses a variety of techniques, including mutation breeding, to obtain a desired trait, such as pest resistance. GMO/GE technology, in contrast to conventional breeding, can be used to introduce a gene to provide resistance against a particular pest. Agriculture scientists and farmers may prefer one methodology over another to obtain the desired result.

tection Agency (EPA) to regulate GMOs. ${ }^{16}$ In 1992, the FDA issued a guidance report that stated its concerns about unknown and un-intended consequences of using biotechnology to alter the food supply. In particular, the FDA was concerned about the increased expression of endogenous toxins or allergens due to genetic modifications. ${ }^{17}$

In the ensuing years, scientists have learned much about plant genomes and genetic engineering. Plant genomes are highly elastic with many genetic changes and gene expression pattern changes occurring at a much higher frequency than previously thought. ${ }^{18}$ The risk of increased expression of endogenous toxins or allergens based on small changes to the genome is no greater than conventional breeding. ${ }^{19}$ The scientific consensus is that genetically engineered food is as safe as conventional food. ${ }^{20}$

Surveys throughout the past several years demonstrate that consumers have concerns about food derived from GMOs/GE and that an overwhelming majority of consumers want labeling. ${ }^{21}$ A survey con- leagues suggested a number of reasons why consumers may prefer organic. ${ }^{25}$ Among some of the most important reasons consumers preferred organic food were health, safety, and the environment. This report also noted that consumers may turn to organic after having a child. ${ }^{26}$ If consumers want the opportunity to choose healthier, safer, and more environmentallyfriendly foods, then it seems reasonable to have labels that provide that information.

Consumers' concerns about modified food products may vary as a function of the product type. Consumers have expressed concerns, for example, that products from GMOs are unsafe or toxic. ${ }^{27}$ This appears to be due to concerns about exposure to the protein product of an inserted foreign gene or increased expression of a natural allergen or toxin. ${ }^{28}$ Some products, such as raw sugar, contain no DNA or protein. ${ }^{29}$ Concerns about ingesting foreign proteins and modified DNA are not applicable for such products. To see if consumers had different reactions to foods depending on whether they contain proteins/enzymes, we compared 
different food products in our survey, including raw sugar, a multi-ingredient product such as cereal, and fruit.

Anecdotal reports have suggested that there may be more safety concerns with organic produce compared to conventional due to the use of manure as a fertilizer by organic farmers. ${ }^{30}$ Additional studies are needed to assess these assertions, but one study found a higher percentage of escherichia coli in produce samples from organic farms (9.7\%) compared to conventional farms $(1.6 \%) .{ }^{31}$ The striking comparison of safety in organic versus conventional produce decreases dramatically when only evaluating escherichia coli prevalence in certified organic produce. ${ }^{32}$ Put differently, the safety of organic and conventional produce appears to vary by farmer.

It seems clear that consumers are concerned about health, safety, and the environment, and that these are prevailing reasons for the calls for mandatory labeling. In other words, consumers seek to make informed food choices. Health, safety, and environmental concerns are not clearly defined, and it appears that these categories may be overlapping. Consumers are concerned about ingesting allergens - this could be either a health or safety concern. Consumers are concerned about ingesting food treated with pesticides or herbicides - this could be a safety and environmental concern. This study aimed to tease out whether consumers differentially associate health, safety, and the environment with different food labels and food products.

Given the reports and scientific studies on a variety of food products, an issue arises as to whether proposed mandatory labeling laws would accurately provide the information that consumers are seeking. The concept of mandatory food labeling can be neutral, so long as the label is providing the intended information. If consumers want to know that a product is safe to eat, then a label can and should provide that information. A primary concern about mandatory labeling of food as GMO, natural, or otherwise is that these labels would not necessarily provide the information that consumers say they want to know.

One approach to creating labeling laws that appropriately inform consumers is to understand the associations they make with different types of labeling (proposed or otherwise). If consumers want to know about health, safety, and the environment, as indicated in the Vermont labeling law, then it is important to know whether they perceive that labeling a product as "natural" or "GMO" provides that information to them. To this end, the present study surveyed consumers and assessed their responses to labeling of a variety of food products. The following questions were addressed:
(1) whether consumers associate health, safety and environment with the following labels: "organic," "natural," "low fat or fat free," "GMO" or "non-GMO"; (2) whether consumers with small children associate health, safety, and environment with the above stated labels differently than consumers who do not have small children; (3) whether consumers associate health, safety, and environment in a different way depending on the type of food such as fruit, cereal, or sugar; and (4) whether consumers associate health, safety, and the environment with different farming practices.

Our hypotheses were the following: (1) consumers would respond that food labeled "organic" was healthier, safer, and more environmentally friendly compared to other food products; (2) consumers with small children would perceive that food labeled "organic" is healthier, safer, and better for the environment compared to consumers without small children; (3) consumers would view the labels on produce differently than other food products; and (4) consumers would associate health, safety, and the environment more positively with organic farmers compared to conventional or GMO farmers.

\section{Study Data and Methods}

\section{Study Design and Sample}

Invitations to complete a food labeling survey consisting of initial demographic information and 10 questions (containing 48 responses) were sent via email to the law school community at California Western School of Law (CWSL) (survey available from the first author). An announcement to participate in the survey was published in the CWSL calendar, which is also distributed by a weekly email. Reminders were also distributed via email during the period in which the survey remained open. The survey was distributed to approximately 1021 recipients. A total of 185 subjects responded to the survey. Of these, $103(55.7 \%)$ were students, 24 (13.0\%) were adjunct faculty, 26 (14.1\%) were full-time faculty, and $32(17.3 \%)$ were staff. Approximately one-third $(\mathrm{n}=68,36.8 \%)$ reported having children, and $30(16.2 \%)$ reported having children 10 years old or younger. During the first two hours that the survey was open, one item in the survey was incorrectly coded such that participants were required to rank order food products rather than rating each product independently. A total of 4 participants completed the survey before the error was corrected; these individuals were excluded from subsequent analyses.

The CWSL community was chosen as a sample due to the wide range of consumers from different backgrounds and at different phases of life. Although the 
survey did not ask about ethnicity, approximately $35 \%$ of the CWSL student body identifies as non-white. ${ }^{33}$ All respondents were adults and therefore either make their own food decisions or at least are at the phase of life to make those decisions.

\section{Survey Instrument}

After reporting their position at the law school (full time faculty, adjunct faculty, staff, or student), participants were asked if they had children. If participants had children, they were then asked if their children were in the following age ranges: 0-10, 11-20, 21 and older. The participants were then presented with 48 questions concerning food labels. Participants were asked to rate how healthy, safe, or environmentally friendly a particular food product was compared to others with the following labels: organic, natural, fat free or low fat, GMO, and non-GMO (45 items). The food products were a multi-ingredient product such as cereal, a raw product such as sugar, and a piece of produce such as an apple. Participants rated each item on a scale from 1-5: 1 (much less healthy/safe/environmentally friendly), 2 (a little less healthy/safe/environmentally friendly), 3 (about the same), 4 (healthier/ safer/environmentally friendly), and 5 (much healthier/safer, environmentally friendly). Participants were also asked how they viewed the motives of organic, conventional, and GMO farmers with the following rating scale: 1 (efficiency regardless of health, safety and being environmentally friendly), 2 (efficiency with some regard for health, safety and being environmentally friendly), 3 (about the same), 4 (health, safety and environment with some regard for efficiency) and 5 (health safety and environment regardless of efficiency).

\section{DataAnalysis}

Hypothesis tests were conducted using mixed effects regression models that compared respondents' perceptions of the extent to which products are healthy, safe, and environmentally friendly. Within-subjects factors included product label (organic, natural, low fat or fat free, GMO, non-GMO) and product (multiingredient (cereal), fruit (apple), raw (sugar)). Both label and product were treated as repeated measures factors, yielding a total of 15 ratings per subject for each outcome (i.e., one rating for each possible combination of label and product). Between-subjects factors included academic status (student, staff, adjunct faculty, full time faculty) and whether respondents had children 10 years old or younger. Separate models were fit for each outcome (healthy, safe, environmentally friendly). GMO was specified as the reference category for the label variable, and multi-ingredient as the reference category for the product variable. Each model initially included an ingredient $\mathrm{X}$ label interaction term; if the interaction was not significant, then it was removed and the model re-fit. Farmers' motives were similarly assessed using a separate mixed effects model that included farmer type (organic, GMO, conventional) as a within-subjects factor and academic status and having young children as between-subjects factors. All analysis were conducted with Stata 14.0 (StataCorp, College Station, TX), with $\alpha=.05$.

\section{Study Results}

Participants' mean ratings of the health, safety, and environment by label and by product are shown in Figure 1. The models for ratings of product healthiness, safety, and environmental friendliness are shown in Tables 1-3, respectively. Findings were very similar across outcomes. In each model, the ingredient $\mathrm{X}$ label interaction was non-significant and the term was removed. Similarly, academic status and having children aged 10 or younger were not significantly related to any of the three outcomes. Ratings of healthiness, safety, and environmental friendliness did not differ significantly across product ingredient categories. In contrast, respondent ratings were significantly different across label types. For each outcome, products labeled "GMO" received significantly less positive ratings compared with other products. Adjusted for the other variables included in the model and across the three outcomes, GMO products were rated as 0.4-0.6 points lower than non- or low-fat products, and 1.1-1.8 points lower than products labeled organic, natural, or non-GMO. We then re-fit the models with non- or low-fat as the reference category. These post-hoc analyses indicated that, while non/low-fat products were rated significantly more positively than GMO-labeled products across outcomes, they were rated significantly less positively than products labeled organic, natural, and non-GMO.

Finally, the analyses of farmers' motives produced similar results. Respondents' ratings of motives were not significantly associated with academic status or whether they had children aged 10 or younger. However, there were significant differences in motives across the three categories. More specifically, GMO farmers were rated significantly less positively than both organic $(z=-17.65, p<.001)$ and conventional $(z$ $=-7.66, p<.001)$ farmers. Post-hoc analyses indicated that the motives of organic farmers were also rated as significantly more positive compared with those of conventional farmers $(z=9.99, p<.001)$. 
Figure I

Health, Safety, and Environment by Label and by Product

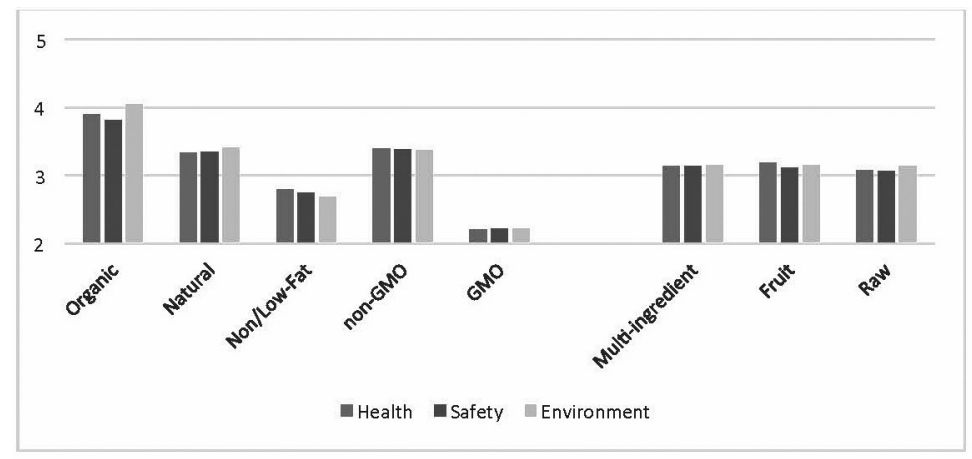

Table |

Perceived Healthiness of Food Products by Label

\begin{tabular}{|c|c|c|c|c|c|}
\hline Category & Predictor & Coefficient & Std. Err. & z-score & p-value \\
\hline \multirow[t]{2}{*}{ Demographics } & Academic status & -0.01 & 0.01 & -0.08 & .938 \\
\hline & Children $<10$ & -0.03 & 0.04 & -0.67 & .505 \\
\hline \multirow[t]{3}{*}{ Food product } & Multi-ingredient (ref) & & & & \\
\hline & Fruit & 0.06 & 0.04 & 1.44 & .148 \\
\hline & Raw & -0.04 & 0.04 & -1.10 & .272 \\
\hline \multirow[t]{5}{*}{ Label } & GMO (ref) & & & & \\
\hline & Organic & 1.71 & 0.05 & 34.66 & $<.001$ \\
\hline & Natural & 1.15 & 0.05 & 23.21 & $<.001$ \\
\hline & Non- or low-fat & 0.59 & 0.05 & 11.98 & $<.001$ \\
\hline & Non-GMO & 1.20 & 0.05 & 24.33 & $<.001$ \\
\hline
\end{tabular}

Table 2

Perceived Safety of Food Products by Label

\begin{tabular}{|c|c|c|c|c|c|}
\hline Category & Predictor & Coefficient & Std. Err. & z-score & p-value \\
\hline \multirow[t]{2}{*}{ Demographics } & Academic status & 0.01 & 0.01 & 0.46 & .649 \\
\hline & Children $<10$ & -0.06 & 0.04 & -1.36 & .173 \\
\hline \multirow[t]{3}{*}{ Food product } & Multi-ingredient (ref) & & & & \\
\hline & Fruit & -0.01 & 0.04 & -0.15 & .882 \\
\hline & Raw & -0.06 & 0.04 & -1.72 & .085 \\
\hline \multirow[t]{5}{*}{ Label } & GMO (ref) & & & & \\
\hline & Organic & 1.59 & 0.05 & 33.17 & $<.001$ \\
\hline & Natural & 1.14 & 0.05 & 23.66 & $<.001$ \\
\hline & Non- or low-fat & 0.53 & 0.05 & 11.05 & $<.001$ \\
\hline & Non-GMO & 1.17 & 0.05 & 24.39 & $<.001$ \\
\hline
\end{tabular}


Table 3

Perceived Environmental Friendliness of Food Products by Label

\begin{tabular}{llcccc}
\hline Category & Predictor & Coefficient & Std. Err. & z-score & p-value \\
\hline Demographics & Academic status & -0.01 & 0.01 & -0.63 & .530 \\
& Children $<10$ & -0.02 & 0.04 & -0.53 & .595 \\
& & & & \\
\hline Food product & Multi-ingredient (ref) & & & & \\
& Fruit & -0.01 & 0.04 & -0.06 & .955 \\
& Raw & -0.02 & 0.04 & -0.59 & .554 \\
& & & & \\
\hline Label & GMO (ref) & & & & \\
& Organic & 1.83 & 0.05 & 36.07 & $<.001$ \\
& Natural & 1.20 & 0.05 & 23.67 & $<.001$ \\
& Non- or low-fat & 0.45 & 0.05 & 8.98 & $<.001$ \\
& Non-GMO & 1.16 & 0.05 & 22.91 & $<.001$ \\
\hline
\end{tabular}

\section{Discussion}

This study investigated consumers' perceptions of health, safety and the environment associated with different food labels. As hypothesized, we found that respondents were significantly more likely to find that food labeled organic was considered healthier, safer and more environmentally friendly than food labeled GMO, regardless of food product. We also found that respondents were significantly more likely to view all other labels tested (natural, fat free or low fat, and non-GMO) as healthier, safer, and more environmentally friendly than food labeled GMO, regardless of food product. Ratings were not associated with differences in food products (i.e., cereal, sugar, and fruit).

Given the reports that consumers may make different food choices if they have small children, we tested whether respondents with small children (ages 0-10) made different associations regarding health, safety, and the environment compared to respondents without small children. We did not find a significant difference between the groups. While it is possible that this study was underpowered to detect this difference, mean safety, health, and environment ratings for the two groups were very similar and not suggestive of a meaningful difference.

Interestingly, respondents associated food with the label "natural" to be as healthy, safe, and environmentally friendly as other types of food labels, except those labeled GMO. Given that the FDA has repeatedly refused requests to define this term, it has no precise regulatory definition. Our results suggest that the label "natural" means something to respondents
- that is, the perceived meaning of "natural" may be similar to "organic" for a typical consumer. Without a clear definition of "natural," it can be suggested that this label does not actually provide meaningful information, although respondents appear to associate certain qualities with the label.

The responses that GMO labeled food is less safe than food with other labels suggests a disconnect between respondent attitudes and the scientific consensus. The American Association for the Advancement of Science has adopted the scientific consensus regarding GMO food and stated: "It is the long-standing policy of the Food and Drug Administration (FDA) that special labeling of a food is required if the absence of the information provided poses a special health or environmental risk. The FDA does not require labeling of a food based on the specific genetic modification procedure used in the development of its input crops. Legally mandating such a label can only serve to mislead and falsely alarm consumers." ${ }^{34}$ The American Medical Association (AMA) issued a similar statement: "Our AMA believes that as of June 2012, there is no scientific justification for special labeling of bioengineered foods, as a class, and that voluntary labeling is without value unless it is accompanied by focused consumer education." ${ }^{35}$ In May 2016, the National Academies of Science issued a comprehensive report about genetically engineered food and provided a number of conclusions, including for example: "[T] he research that has been conducted in studies with animals and on chemical composition of GE food reveals no differences that would implicate a higher 
risk to human health from eating GE foods than from eating their non-GE counterparts." ${ }^{36}$ Thus, participants indicated an association of health, safety, and environmental friendliness with labeling that does not align with the positions of major scientific and medical associations. with sustainability - and organic farming is not immune from these issues. ${ }^{37}$ The different techniques to control weeds, eliminate pests, fertilize the soil, irrigate, etc., have sophisticated environmental consequences. Our results suggest, however, that consumers do associate better health, safety, and environmental

\section{Our results confirmed only some of our hypotheses: (1) respondents associate greater health, safety and environmental friendliness with all labels compared to the GMO label; (2) we did not find any difference in associations between respondents with small children compared to those without small children; \\ (3) no difference in responses were seen among food products; and (4) respondents positively associate health, safety, and the environment with organic farmers compared to conventional and GMO farmers.}

In sum, our results confirmed only some of our hypotheses: (1) respondents associate greater health, safety and environmental friendliness with all labels compared to the GMO label; (2) we did not find any difference in associations between respondents with small children compared to those without small children; (3) no difference in responses were seen among food products; and (4) respondents positively associate health, safety, and the environment with organic farmers compared to conventional and GMO farmers.

Interestingly, respondents saw the three outcome measures as essentially identical. Put differently, the means for health, safety, and environment are all extremely close, regardless of food product. One reason for this could be that these categories are not clearly defined and are likely overlapping in terms of consumer perceptions. Respondents could consider herbicide use as a concern for health, safety, and the environment.

Respondents also did not differentiate based on food product. Given the expressed concerns about ingestion of a foreign protein or allergen, we tested whether respondents responded differently to a food product, such as sugar, which does not contain protein. Also, despite some anecdotal reporting that organic produce might have a lower safety rating compared to conventional produce, we tested an apple as a food product. Overall, the type of food product tested was not associated with differences in associations of health, safety, and environmental friendliness. It was the label that had the significant effect.

The environmental component is likely more nuanced than the typical information known by consumers. Agriculture and farming have many issues motivations with organic farmers. These associations may provide an underlying reason for the strong association of health, safety, and environment of organic labeling for food products.

The study may provide helpful information in drafting new labeling laws or guidelines. First, proposals for mandatory labeling laws cite health, safety, and the environment as main rationales. If this is the information that consumers want to know, then the label should provide that information. The results of this study suggest that respondents incorrectly associate health, safety, and the environment with various labels. Strikingly, the results of our survey show that the terms "organic" and "natural" have similar results, even though the term "natural" is not defined. Second, labeling laws should provide neutral information. In this study, we found that respondents think a GMO label means that the food is less healthy, less safe, and less environmentally friendly compared to products with other labels. These associations suggest that the mandatory labeling laws may not be neutral as applied.

Our survey results also suggest that respondents associate different motivations for farming practices with different labels. One possible explanation for this may be a consumer dislike of the corporate practices of major GMO producers. Another reason could be that consumers associate organic farming as a return to a more natural state. Although our results do not and cannot specify the reasons, the results demonstrate that the associations were significant in this sample.

The results of this study may provide important insight for mandatory food labeling laws. It would be important to know whether, for example, the associa- 
tions found in the results of our survey may be due to marketing techniques used to persuade consumers to make these associations. It is possible that consumers are calling for labels to confirm what they are learning through marketing campaigns. Future studies can be aimed at understanding why these associations exist.

Another possible reason to explore these associations is consumers' perceptions of risk. Studies show that people are more likely to accept a known, but higher, risk compared to an unknown, even if lower, risk. ${ }^{38}$ Since the technology for GMO is newer than the technology for conventional breeding, consumers may be risk-adverse. Studies also show that heavy regulation can have the opposite effect on public perception and confidence. ${ }^{39}$ Thus, mandatory labeling just for the sake of labeling may make shake consumer understanding of and confidence in GMO food products.

Our study is not without limitations. First, we used a small survey in an attempt to understand a much larger topic. The rationale for using a small number of questions was to create a less burdensome survey. A larger number of questions, however, comes with its own limitations, such as fewer respondents. Second, we had only 185 respondents from a law school community. While the survey was distributed to an ethnically diverse sample, it may not be representative of US consumers as a whole. A third limitation is that some of the respondents may be familiar with the first author's research regarding food policy, especially addressing GMOs. This limitation would likely lead to biased answers, but the bias would likely have led to results that were not significant. Fourth, it is possible that some respondents did not answer honestly, which can also bias the results.

To our knowledge, this is the first survey to attempt to understand consumer reactions regarding health, safety, and the environment to various labeling of different food products. It is possible that these results could be useful to provide insight as to how labels can be drafted to provide the information that the consumer thinks they are getting or provide the information that the consumer wants to know.

\section{Acknowledgment}

We thank Christopher Robertson for his comments on a draft of the manuscript.

\section{References}

1. "Campbell Announces Support for Mandatory GMO Labeling," (2016), available at <http://www.businesswire.com/news/ home/20160107006458/en/Campbell-Announces-SupportMandatory-GMO-Labeling> (last visited October 28, 2016).

2. E.g., J. Hamblin, "No One Is Denying a 'Right to Know What's in My Food," The Atlantic, July 24, 2015, available at $<\mathrm{http}$ :// www.theatlantic.com/health/archive/2015/07/no-one-is-deny- ing-a-right-to-know-whats-in-my-food/399536/> (last visited October 28, 2016).

3. "GE Food Labeling: States Take Action" (2014), available at <http://www.centerforfoodsafety.org/fact-sheets/3067/gefood-labeling-states-take-action> (last visited October 28, 2016).

4. 9 V.S.A. \$3041 et seq. (2013-14), An Act Relating to the Labeling of Food Produced with Genetic Engineering.

5. Id.

6. "National Bioengineered Food Disclosure Standard," available at <http://www.agriculture.senate.gov/imo/media/doc/ Mandatory\%20Labeling\%20Bill.pdf> (last visited October 28, 2016) (amending The Agricultural Marketing Act of 1946, 7 U.S.C. 1621 et. seq.).

7. "FDA Takes Several Actions Involving Genetically Engineered Plants and Animals for Food," November 19, 2015, available at <http://www.fda.gov/NewsEvents/Newsroom/PressAnnouncements/ucm473249.htm> (last visited October 28, 2016).

8. Id.

9. FDA, "What Is the Meaning of 'Natural' on the Label of Food?" available at <http://www.fda.gov/aboutfda/transparency/ basics/ucm214868.htm> (last visited October 28, 2016).

10. Id.

11. E.g., O. Leyser, "Moving beyond the GM Debate," PLoS Biology 12, no. 6 (2014): e1001887.

12. G. Miah, M. Y. Rafii, M. R. Ismail, A. B. Puteh, H. A. Rahim, R. Asfaliza, and M. A. Latif., "Blast Resistance in Rice: A Review of Conventional Breeding to Molecular Approaches," Molecular Biology Reports 40, no. 3 (2013): 2369-2388; G. Conko, D. L. Kershen, H. Miller, and W. A. Parrott, "A RiskBasaed Appraoch to the Regulation of Genetically Engineered Organisms," Nature Biotechnology 34, no. 5 (2016): 493-503.

13. $I d$.

14. FDA, "Consumer Info about Food from Genetically Engineered Plants," 2015, available at <http://www.fda.gov/Food/ FoodScienceResearch/GEPlants/ucm461805.htm> (last visited October 28, 2016).

15. See Miah et al., supra note 13; S. H. Strauss and J. K. Sax, "Ending Event-Based Regulation of GMO Crops," Nature Biotechnology 34, no. 5 (2016): 474-477; N. Weber, C. Halpin, L. C. Hannah, J. M. Jez, J. Kough, and W. Parrott, "Editor's Choice: Crop Genome Plasticity and Its Relevance to Food and Feed Safety of Genetically Engineered Breeding Stacks," Plant Physiology 160, no.4 (2012): 1842-53.

16. J. P. Holdren, H. Shelanski, D. Vetter, and C. Goldfuss, "Improving Transparency and Ensuring Continued Safety in Biotechnology", July 2, 2015, available at <https://www.whitehouse.gov/blog/2015/07/02/improving-transparency-andensuring-continued-safety-biotechnology> (last visited October 28, 2016).

17. FDA, "Statement of Policy - Foods Derived from New Plant Varieties," available at <http://www.fda.gov/Food/GuidanceRegulation/GuidanceDocumentsRegulatoryInformation/Biotechnology/ucm096095.htm> (last visited October 28, 2016).

18. See Weber et al., supra note 16.

19. Id; see Conko et al., supra note 13; see Strauss and Sax, supra note 16 .

20. American Association for the Advancement of Science, Statement by the AAAS Board of Directors On Labeling of Genetically Modified Foods (2012), available at <http://www.aaas. org/sites/default/files/migrate/uploads/AAAS_GM_statement.pdf $>$ (last visited October 28, 2016); C. Snell, A. Bernheim, J. B. Berge, M. Kuntz, G. Pascal, A. Paris, and A. E. Ricroch, "Assessment of the Health Impact of GM Plant Diets in Long-Term and Multigenerational Animal Feeding Trials: A Literature Review," Food and Chemical Toxicology 50, nos. 3-4 (2012): 1134-1148; National Academy of Sciences, Genetically Engineered Crops: Experiences and Prospects, May 17, 2016 , available at <http://www.nap.edu/catalog/23395/geneticallyengineered-crops-experiences-and-prospects $>$ (last visited October 28, 2016). 
21. Deloitte, Deloitte 2010 Food Survey Genetically Modified Foods (2010), avilable at <https://web.archive.org/ web/20101227135642/http://www.deloitte.com/assets/DcomUnitedStates/Local\%20Assets/Documents/Consumer\%20 Business/us_cp_2010FoodSurveyFactSheetGeneticallyModif iedFoods_05022010.pdf> (last visited October 28, 2016); A. Kopicki, "Strong Support for Labeling Modified Foods," New York Times, July 27, 2013, available at <http://www.nytimes. com/2013/07/28/science/strong-support-for-labeling-modified-foods.html?_r=1> (last visited October 28, 2016); Wikipedia, "Genetically Modified Food Controversies," February 2016, available at <https://en.wikipedia.org/wiki/Genetically_modified food controversies> (last visited October 28, 2016).

22. Id. (Kopicki).

23. S. Faber, "Demand for Organic Food Growing Faster than Domestic Supply," 2006, available at <https://www.organicconsumers.org/news/demand-organic-food-growing-fasterdomestic-supply> (last visited October 28, 2016).

24. United States Department of Agriculture, "Organic Agriculture," 2015, available at <http://www.usda.gov/wps/portal/ usda/usdahome? contentidonly=true\&contentid=organic-agriculture.html> (last visited October 28, 2016).

25. R. S. Hughner, P. McDonagh, A. Prothero, C. J. Shultz II, and J. Stanton, "Who are Organic Food Consumers? A Compilation and Review of Why People Purchase Organic Food," Journal of Consumer Behavior 6 (2007): 94-110.

26. Id.

27. See Kopicki, supra note 21; M. Anderson, "Amid Debate over Labeling GM Foods, Most Americans Believe They're Unsafe," 2015, available at <http://www.pewresearch.org/ fact-tank/2015/08/11/amid-debate-over-labeling-gm-foodsmost-americans-believe-theyre-unsafe/> (last visited October 28, 2016).

28. A. S. Bawa, and K. R. Anilakumar, "Genetically Modified Foods: Safety, Risks and Public Concerns-A Review," Journal of Food Science and Technology 50, no. 6 (2013): 1035-1046.

29. Id.

30. M. Popoff, P. Moore, and R. Wager, "Organics versus GMO: Why the Debate?” 2013, available at <http://www.geneticli- teracyproject.org/2013/10/15/organics-versus-gmo-why-thedebate/> (last visited October 28, 2016).

31. A. Mukherjee, D. Speh, E. Dyck, and F. Diez-Gonzalez, "Preharvest Evaluation of Coliforms, Escherichia coli, Salmonella, and Escherichia coli O157:H7 in Organic and Conventional Produce Grown by Minnesota Farmers," Journal of Food Protection 67, no. 5 (2004): 894-900.

32. Id.

33. E.g., California Western School of Law, "Standard 509 Information Report," 2015, available at <https://www.cwsl.edu/ search-results?search $=509>$ (last visited October 28, 2016).

34. See American Association for the Advancement of Science, supra note 21

35. American Medical Association, "H-480.958 Bioengineered (Genetically Engineered) Crops and Foods," 2012, available at <https://www.cga.ct.gov/2013/KIDdata/Tmy/2013HB-06527R000305-AMA\%20Bioenginerred\%20Crops \% 20and \% 20 Foods-TMY.PDF (last visited November 9, 2016).

36. See National Academy of Sciences, supra note 21.

37. H. I. Miller, "Why Organic Isn't 'Sustainable," November 19, 2014, available at <http://www.forbes.com/sites / hen rymiller / 2014 / 11/19/why-organic-is n tsustainable/\#49af3b5937aa> (last visited October 28, 2016).

38. L. L. Blaisdell, C. Gutheil, N. A. M. Hootsmans, and P. K. J. Han, "Unknown Risks: Parental Hesitation about Vaccination," Medical Decision Making 36, no. 4 (2016): 479-489; D. Ellsberg, "Risk, Ambiguity, and the Savage Axioms," Quarterly Journal of Economics 75, no. 4 (1961): 643-669; C. Camerer and M. Weber, "Recent Developments in Modeling Preferences: Uncertainty and Ambiguity," Journal of Risk and Uncertainty 5, no. 4 (1992): 325-370.

39. P. M. Wiedemann and H. Schutz, "The Precautionary Principle and Risk Perception: Experimental Studies in the EMF Area," Environmental Health Perspectives 113, no. 4 (2005): 402405; see also Strauss and Sax, supra note 16. 